\title{
Premarket Device Notification
}

National Cancer Institute

\section{Source}

National Cancer Institute. Premarket Device Notification. NCI Thesaurus. Code C80442.

A premarket submission made to FDA to demonstrate that a device to be marketed is at least as safe and effective as a legally marketed device that is not subject to PMA

(Premarket Authorization). 